\title{
Fabric Hand-Feel Evaluation Based on Neurophysiology: An Event- Related Potential Study
}

\author{
Xiaoxia Zhang ${ }^{1,2}$, Jing Yue ${ }^{1,2}$, Yue Zhang ${ }^{1,2}$ and Guohe Wang ${ }^{1,2, *}$ \\ ${ }^{I}$ College of Textile and Clothing Engineering, Soochow University, Suzhou, China \\ ${ }^{2}$ National Engineering Laboratory for Modern Silk, Suzhou, China
}

\begin{abstract}
Fabric hand-feel is an important indicator of textile comprehensive evaluation. In the past century, many achievements have been made in characterization and evaluation of fabric hand-feel. With the development of experimental methods, the electrophysiological technique was used in exploring the formation mechanism and cognitive principle of fabric hand-feel. In this paper, event-related potential (ERP) technique was used in revealing the difference of handfeel between polyester and silk. The exogenous component P2 showed that polyester caused more excitability in human brain. However, the endogenous component P3 indicated that silk caused more soft and comfortable feelings. Even more amazingly, touching fabrics caused significant activation of the visual cortex from the Brain Electrical Activity Mapping (BEAM), and it is also shown that the potential distribution evoked by grasping silk is wider than the polyester's. All the experiment results show that potential variation of the cerebral cortex is closely related to perceptual cognition and process. All the above findings show that event-related potential technique is feasible and effective in detecting the differences of tactile cognition, and it provides objective evidence from neurophysiologic in fabric hand-feel research.
\end{abstract}

Keywords: Brain topographic map, event-related potential, fabric hand-feel, P2 component, P3 component.

\section{INTRODUCTION}

Fabric hand-feel evaluation is a complex and dynamic cognitive process. When fingers move across a fabric's surface, a signal was evoked by tactile receptors, it is transmitted from the receptors, passes via sensory nerves through tracts in the spinal cord into the brain. Finally, the tactile information is processed by the primary somatosensory area which is in the parietal lobe of the cerebral cortex [1]. However, the cognition of fabric hand-feel is not only the tactile signal input and output, but also accompanied by human mental and neurocognitive processes.

Around subjective and objective evaluation of fabric hand-feel, there were already a large number of achievements. In this area, three common methods were adopted for textile tactile research; they are Psychophysical method [26], Physical index method [7-11], and Electrophysiological method [12-16].

Many scholars did a lot of research using the first two methods, but due to the limitation, they can't reveal the physiological mechanism of fabric hand-feel, and their results deviated from people's cognitive laws [17]. With the development of technology, electrophysiological technique as a method was introduced into the fabric hand-feel research [18-22]. A handful of scholars recorded the evoked potential

\footnotetext{
*Address correspondence to this author at the National Engineering Laboratory for Modern Silk, Suzhou, China; Tel: 15950055699; E-mail: summer-hades@163.com
}

or discharge rate curve when the human body (such as fingertip, ventral and dorsal forearm) contacts with the fabric's surface, and extracted the characteristic value, then analyzed the relationship between fabric physical properties and characteristic value.

Pan et al. $[23,24]$ recorded the electromyography signals when fingertip and forearm ventral ran across fabric's surface, discovered that forearm ventral has low resolution for roughness and smoothness. When fingers move parallel along the surface or vertically thrusting the fabric could obtain most sensory information, and the spatial resolution of tactile receptors are shown in Fig. (1). However, existing research has failed to fully extract sensory information, and physiological data is difficult to distinguish fabrics with unobvious perception differences. Therefore, research of electrophysiology still stays in a qualitative analysis stage.

A few achievements have already been done in electromyography (EMG), but research on fabric hand-feel in electroencephalogram (EEG) has not be reported yet. In this study, event-related potential (ERP) was used in detecting the cognitive differences between polyester and silk. Moreover, it was tried to prove the feasibility of this method and provide an evidence from EEG signal for electrophysiology method in fabric hand-feel research.

\section{METHODS}

Principle: ERP are voltage fluctuations in the electroencephalogram (EEG) induced within the brain that is time locked to sensory, motor, or cognitive events. They provide a direct, non-invasive measure of the temporal course of the 


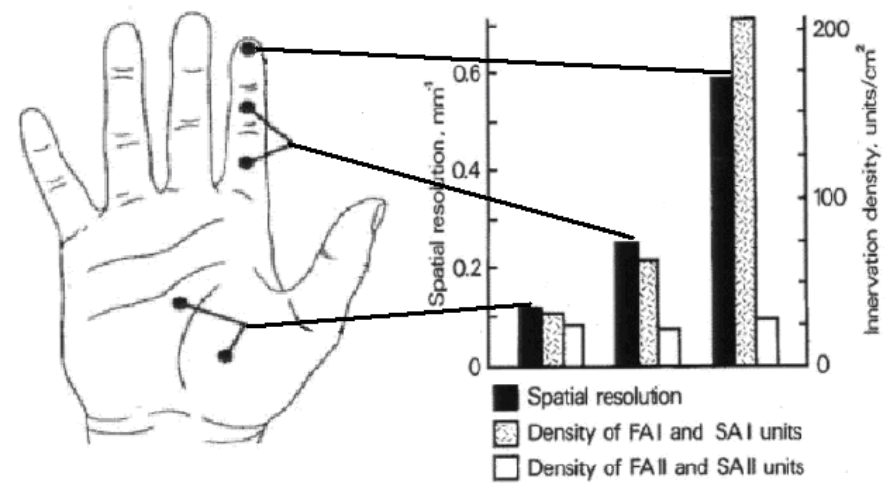

Fig. (1). The spatial resolution of tactile receptors.

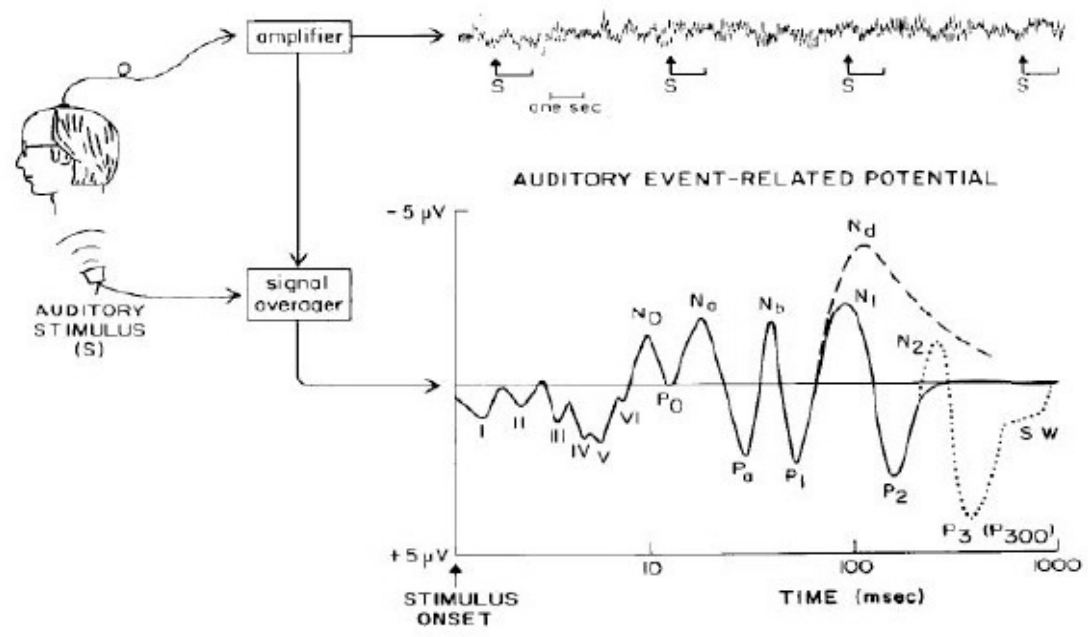

Fig. (2). The Principle of Event-Related Potential.

voltage changes that are extremely sensitive to manipulations of the cognitive context within which the eliciting stimuli are embedded. By contrast, the spatial resolution for the identification of the neural sources generating these signals has been poorly relative to the newer brain imaging techniques [25]. The Principle of Event-Related Potential is shown in Fig. (2).

Participants: Thirty female graduate students (age range 22-28 years) from Soochow University participated in this experiment. All participants were right-handed, and reported normal or corrected-to-normal vision, and had no history of current or past neurological or psychiatric illness and took no medications known to affect the central nervous system.

Electrophysiological Recording: EEG was recorded continuously by a set of $30 \mathrm{Ag} / \mathrm{AgCl}$ electrodes placed according to the 10/20 system [26] shown as Fig. (3). The data recording sites were: FP1, FP2, F7, F3, Fz, F4, F8, FT7, FC3, FCz, FC4, FT8, T7, C3, Cz, C4, T8, TP7, CP3, CPz, CP4, TP8, P7, P3, Pz, P4, P8, O1, O2 and Oz. The tip of the nose was used as reference during recording, and a common average reference was calculated off-line. EEG were sampled at $1000 \mathrm{~Hz}$, with a $0.1-100 \mathrm{~Hz}$ band pass using a Neuroscan Nuamps digital amplifiers system. Electrode impedances were kept below $5 \mathrm{k} \Omega$.
Stimuli and Task: The stimuli were 2 kinds of fabrics, polyester and silk, of the same standard, white color and 20 $\mathrm{cm} \times 20 \mathrm{~cm}$ size. An oddball paradigm was used, subjects performed both a two-tone oddball task and a tactile oddball task; the task was to distinguish fabrics by touching. In each, standard stimuli $(\mathrm{p}=0.75)$ were $1000 \mathrm{~Hz}$ tones and targets $(\mathrm{p}=0.25)$ were $2000 \mathrm{~Hz}$ tones. Along with the target tones occurrence, participants were required to grasp the fabrics in front of them at time interval between each tone for 2 seconds. Participants were tested in a dimly lit room. They sat in a comfortable chair with their eyes closed during the whole process. The process of this experiment is shown in Fig. (4).

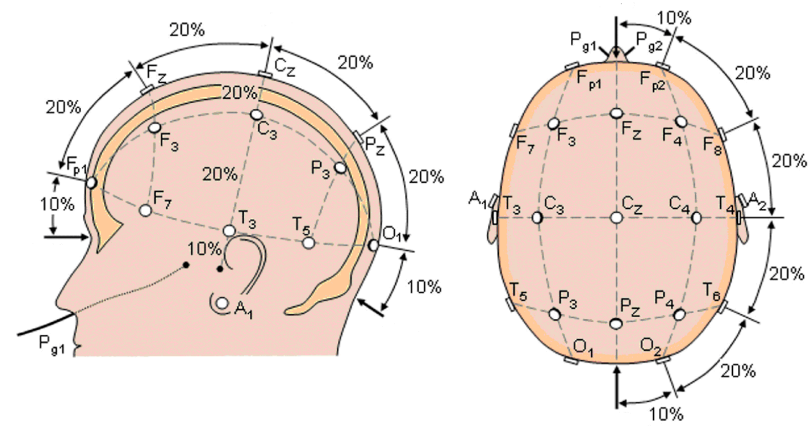

Fig. (3). The 10-20 electrode system of the International Federation. 


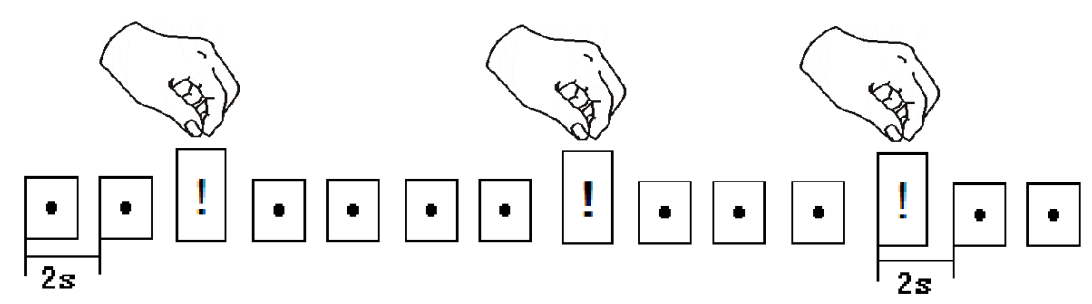

Fig. (4). The process of this experiment.
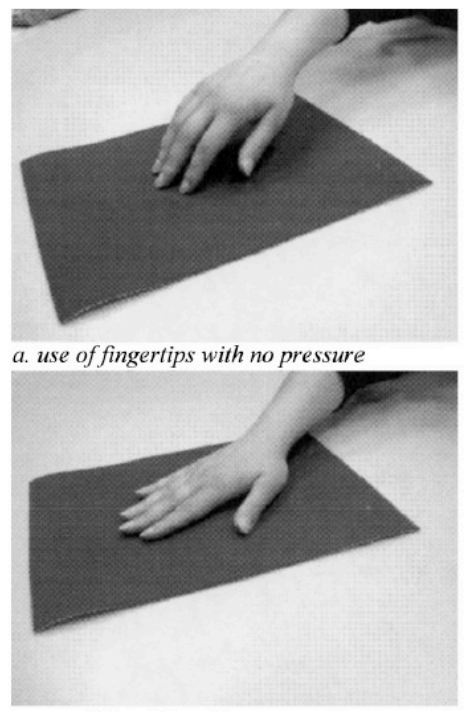

c. use of the palm with no pressure

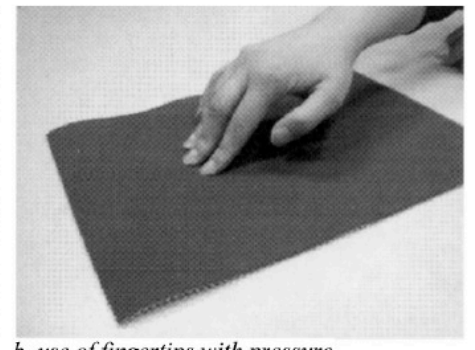

b. use of fingertips with pressure

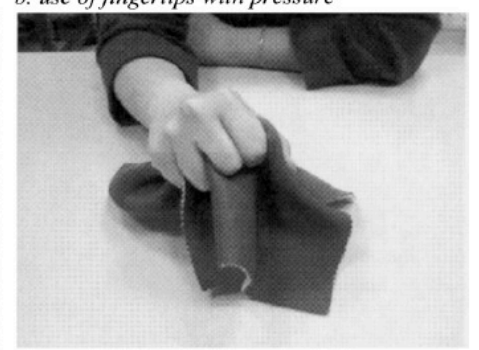

d. use of all hand with manipulation

Fig. (5). Hand-style in fabric hand-feel evaluation.

In many studies, there were many differences between evaluation index and fabric hand-feel by each hand-styles [27], in general, four hand-styles were usually used in evaluating one property of fabric; they are shown in Fig. (5).

a. Palm natural state down on fabric surface, which is associated with the description of the overall performance of the fabric, such as the sense of comfort, softness, fullness;

b. Fingertips contact fabric surface at a certain pressure, sense evaluation and softness of the fabric thickness;

c. With fingertips contacting surface of the fabric under natural state, with local or a wide range of movement, the roughness of evaluating fabric, surface morphology, stickslip, finger activity can be circular, can also be a linear movement;

d. With five fingers to grasp or pinch the fabric, evaluation of fabric stiffness or softness.

In this experiment, it takes stiffness and softness as research target, so we choose grasping with five fingers to evaluate fabric hand-feel. The hand-style in real experiment is shown in Fig. (6).

\section{DATA ANALYSES}

After overlying and averaging the data for 30 times, the waveform of ERP evoked by polyester and silk was shown in Fig. (7).

P2 Component: The P2 component is the second positive peak in the ERP, occurring at around $150 \mathrm{~ms}$ to $300 \mathrm{~ms}$ after stimulus onset, it is one of the exogenous components in the ERP and depends on stimulus characteristics [28-30]. As presented in Fig. (7) and Table 1, the stimuli of polyester elicited higher amplitude of the P2 component than silk ones, and the maximum value of potential evoked by polyester is larger than silk, which showed that the physical characteristics of polyester can cause much more brain excitability than silk.

P3 Component: The P3 component is the third positive peak in the ERP; it is usually largest at parietal and central electrode locations with a peak time of about 300-600 ms after stimulus onset [31-33], so P3 is also called P300. P3 (or

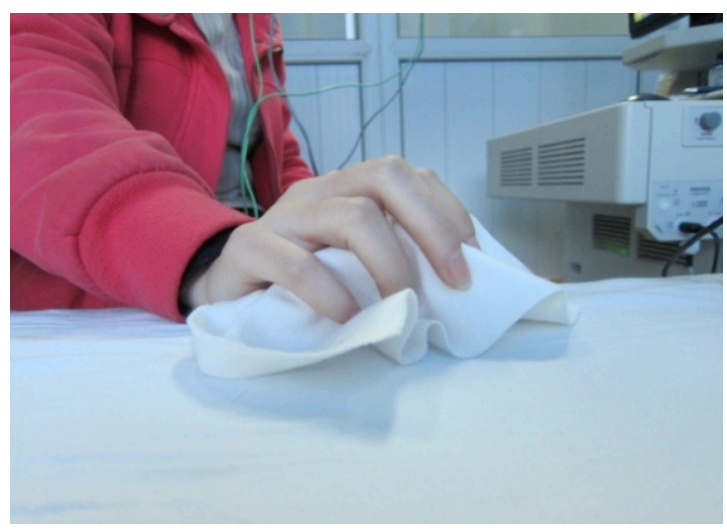

Fig. (6). The photo of hand-style in real experiment. 


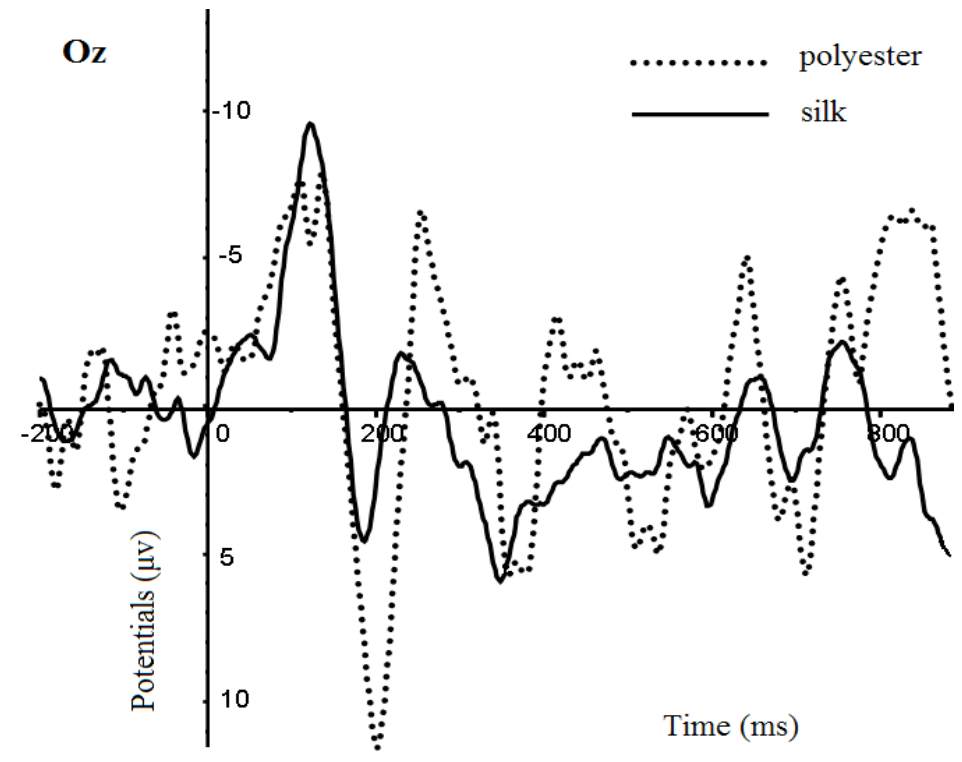

Fig. (7). The waveform of ERP evoked by polyester and silk.
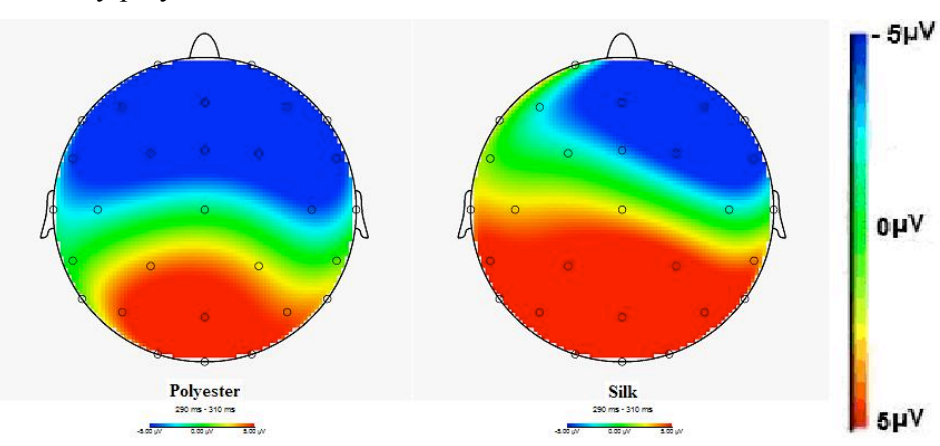

Fig. (8). The brain topographic map in 290-310ms.

Table 1. The data of $P 2$ component and $P 3$ component.

\begin{tabular}{|c|c|c|c|c|c|c|}
\hline & \multicolumn{3}{|c|}{ P2 } & & \multicolumn{2}{c|}{ P3 } \\
\hline Sample & Max. & Amplitude & Latency & Max & Amplitude & latency \\
\hline \hline Silk & 4.8 & 14.4 & $187 \mathrm{~ms}$ & 6.0 & 7.9 & $342 \mathrm{~ms}$ \\
\hline Polyester & 11.7 & 19.7 & $203 \mathrm{~ms}$ & 5.7 & 12.5 & $367 \mathrm{~ms}$ \\
\hline
\end{tabular}

P300) reflects cognitive processing, such as stimulus densifications and elaboration, and its amplitude is thought to reflect resource allocation of attention [34-36]. The amplitude and latency of this component can be used as the markers of the cognitive processes. Many researches show that there is a close contact between the P300 wave and fabric tactile, different softness of fabrics cause the difference of P300 amplitude. In other words, the fabrics with soft, smooth and comfortable feelings evoked the lower P300 amplitude, whereas the rough or uncomfortable fabrics caused the higher amplitude [37]. As presented in Table 1, polyester automatically elicited higher amplitudes of the P3 component than silk, it means that participants feel more soft and comfortable when they grasp the silk. In conclusion, the amplitude of P3 component can be used as the physiological evidence to distinguish the softness, smoothness and comfort of fabrics.
Brain Topographic Map: Brain topographic map refers to the brain waves of internal power spectrum. Values expressed in different colors of spherical scalp are exhibited through a simple figure, as one of the important ways to study brain function and clinical diagnosis, which are widely used. The topographic map in 290-310 ms is shown in Fig. (8).

An amazing finding that we can see from Fig. (8) is that in this tactile exam, participants grasp fabrics to evaluate the hand-feel without visual assistance. However, the visual cortex was activated by both polyester and silk in the process of touch sense and judgment, and the activation area evoked by silk was much larger than the polyester. We deduce that the reason of this phenomenon may be associated with the learning procedure of human. Almost every human learns and understands the world through the eyes, when we recognize 
the fabrics only by touch, we may visualize a scene in our brain according to our experience in daily life. But the physiological mechanism and cognitive principle still need further verification.

\section{CONCLUSION}

In this research, the event-related potential method was used in fabric hand-feel evaluation. The fine-grained temporal information provided by scalp-recorded and intracranial ERP data converge suggested that the polyester caused more excitability in human brain. Moreover, silk gave more soft and comfortable feelings than polyester. In a word, the event-related potentials technology is a feasible and effective method used in fabric hand-feel research.

\section{CONFLICT OF INTEREST}

The authors confirm that this article content has no conflict of interest.

\section{ACKNOWLEDGEMENTS}

This work was financially supported by the Priority Academic Program Development of Jiangsu Higher Education Institutions 2011[6] and Jiangsu Natural Science Foundation (JSNSF-BK2012196).

\section{REFERENCES}

[1] R. D. Gabriel, "The importance of the sense of touch in virtual and real environments", IEEE Multimedia, vol. 13, no. 3, pp. 24, 2006.

[2] I. Soufflet, M. Calonnier and C. Dacremont, "A comparison between industrial experts' and novices' haptic perceptual organization a tool to identify descriptors of fabric hand-feel", Food Quality Prefer., vol. 15, no. 7-8, pp. 689-699, 2004.

[3] F. You, J. M. Wang X. N. Luo Y. Li, and X. Zhang, "Garment's pressure sensation (2): The psychophysical mechanism for the sensation”, Int. J. Clothing Sci. Technol., vol. 14, no. 5, pp. 317-327, 2002.

[4] F. Philippe, L. Schacher, D. C. Adolphe, and C. Dacremont, "Tactile feeling: Sensory analysis applied to textile goods", Textile Res. $J$. , vol. 74, no. 12, pp. 1066-1072, 2004.

[5] J. L. Hu, W. X. Chen and A. Newton, "A psychophysical model for objective fabric hand evaluation: an application of stevens law", $J$. Textile Instit., vol. 84, no. 3, pp. 354-363 1993.

[6] R. Chollakup, A. Sinoimeri, and D. Adolphe, "Tactile sensory analysis applied to silk/cotton knitted fabrics", Int. J. Clothing Sci. Technol., vol. 16, no. 1-2, pp. 132-140, 2004.

[7] W. M. B. Tiest, A. M. L. Kappers, "Analysis of haptic perception of materials by multidimensional scaling and physical measurements of roughness and compressibility", Acta Psychol., vol. 121, no. 1, pp.1, 2006..

[8] S. S. Kawabata, "The standardization and analysis of hand evaluation" (Second edition), 1980.

[9] D. Picard, C. Dacremont, D. Valentin, "Perceptual dimensions of tactile textures" Acta Psychol., vol. 114, no. 2, pp. 165-184, 2003.

[10] M. Hollins, R. Faldowski, S. Rao, "Perceptual dimensions of tactile surface texture: a multidimensional scaling analysis", Percept. Psychophys., vol. 54, no. 6, pp. 697-705, 1993.

[11] M. Hollins, S. Bensmaia, K. Karlof, F. Young, "Individual differences in perceptual space for tactile textures: evidence from multidimensional scaling", Percept. Psychophys., vol. 62, no. 8, pp. 1534-1544, 2000.

[12] C. Breugnot, M. A. Bueno, M. Renner, "Mechanical discrimination of hairy fabrics from neurosensorial criteria", Textile Res. J., vol. 76, no. 11, pp. 835-846, 2006.
[13] R. S. Johansson, I. Birznieks, "First spike in ensembles of human tactile afferents code complex spatial fingertip events", Nat. Neurosci., vol. 7, no. 2, pp. 170-177, 2004.

[14] S. Lee, M. Kamijo, "Active tactual motion of fingers in discrimination cloth- the difference between male and female", Sen'i Gakkaishi, vol. 59, no. 9, pp. 57, 2003.

[15] J. W. Morley, A. W. Goodwin, and I. Darian, "Tactile discrimination of gratings", Exp. Brain Res., vol. 49, no. 2, pp. 291-299, 1983.

[16] M. A. Srinivasan, R. H. Lamotte, "Tactual discrimination of softness", J. Neurophysiol., vol. 73, no. 1, pp. 88-101, 1995.

[17] K. O. Johnson, S. S. Hsiao, T. Yashioka, "Neural coding and the basic law of psychophysics", Neuroscientist., vol. 8, no. 2, pp. 111121, 2002.

[18] E. M. Reuter, R. C. Voelcker, S. Vieluf, "A parietal-to-frontal shift in the P300 is associated with compensation of tactile discrimination deficits in late middle-aged adults", Psychophysiology, vol. 50, no. 6 , pp. 583-593, 2013

[19] E. Wronka, J. Kaiser, A. M. Coenen, 2013. "Psychometric intelligence and P3 of the event-related potentials studied with a 3stimulus auditory oddball task", Neurosci. Lett., vol. 535, pp. 110115, 2013.

[20] Y. Liu, J. Gao, W. D. Yu, and N. Pan, "Soft contact of fibrous surfaces”, Int. J. Nonlinear Sci. Num. Simulat., vol. 11, no. 1, pp. 71-79, 2010.

[21] Y. Q. Liu, "Characterization for fabric tactile perception based on functional magnetic resonance imaging and meso-mechanic analysis", Donghua University Doctoral Dissertation, 2009.

[22] X. F. Jiang, "Mechanism for effects of Clothing Color Value on Human Emotion - Behavioral and ERP Study", Soochow University Doctoral Dissertation, 2011

[23] Z. J. Pan, and D. G. Li, "Touch technique physiological mechanism an'd the effect of fabric evaluation", J. Textile Res., vol. 23, pp. 13 , 2002.

[24] D. Friedman, Y. M. Cycowicz, and H. Gaeta, "The novelty P3: an event-related brain potential (ERP) sign of the brain's evaluation of novelty", Neurosci. Biobehav. Rev., vol. 25, no. 4, pp. 355-373, 2001.

[25] S. A. Hillyard, and M. Kutas, "Electrophysiology of cognitive processing", Ann. Rev. Psychol., vol. 34, pp. 33-61, 1983.

[26] H. H. Jasper, "The ten-twenty electrode system of the International Federation", Electroencephalograph. Clin Neurophysiol., vol. 10, pp. 371-375, 1958.

[27] A. Giboreau, S. Navarro, P. Faye, J. Dumortier, "Sensory evaluation of automotive fabrics: the contribution of categorization tasks and non verbal information to set-up a descriptive method of tactile properties", Food Quality Prefer., vol. 12, no. 5, pp. 311-322, 2001.

[28] X. Wang, and Y. Huang, "Event-related potential P2 correlates of implicit aesthetic experience", Neuroreport., vol. 23, no. 14, pp. 862-866, 2012.

[29] M. A. David, "Coordinated Roles of Motivation and Perception in the Regulation of Intergroup Responses: Frontal Cortical Asymmetry Effects on the P2 Event-related Potential and Behavior", $J$. Cog. Neurosci., vol. 22, no. 11, pp. 2609-2617, 2010.

[30] J. Yang, W. Ding, P. F. Chen, Q. L. Zhang, "Images of tactile intimacy in same-sex dyads elicit larger P2 and LPC amplitudes", Neurosci. Lett., vol. 441, no. 2, pp. 215-218, 2008.

[31] A. M. Brouwer, "A tactile P300 brain -computer interface. Front Neurosci., vol. 4, pp. 19, 2011.

[32] M. Brouwer, The TNO tactile P300 BCI”, Neurosci Lett., vol. 500, p. e12, 2011

[33] Benoit, R. Nicolas, "Backward masking during rapid serial visual presentation affects the amplitude but not the latency of the P3 event-related potential", Psychophysiology, vol. 47, no. 5, pp. 942948, 2010.

[34] H. A. Franken, W. Strien, B. R. Bocanegra, "The P3 event-related potential as an index of motivational relevance", J. Psychophysiol., vol. 25 , no. 1, pp. 32-39, 2011.

[35] E. J. Linden, "The P300: Where in the brain is it produced and what does it tell us?", Neuroscientist., vol. 11, no. 6, pp. 563-576, 2005. 
[36] K. Albert, "On the utility of P3 amplitude as a measure of processing capacity", Psychophysiology., vol. 38, no. 3, pp. 557-577, 2001.
[37] H. Yohsuke, K. Masayoshi, H. Satoshi, and T. Masayuki, "Evaluation of tactile sensation for wearing by using event-related potential", Sen'i Gakkaishi., vol. 56, no. 1, pp. 87-92, 2000.

Received: June 09, 2014

Revised: June 22, 2014

Accepted: July 24, 2014

(C) Zhang et al.; Licensee Bentham Open.

This is an open access article licensed under the terms of the Creative Commons Attribution Non-Commercial License (http://creativecommons.org/ licenses/by-nc/4.0/) which permits unrestricted, non-commercial use, distribution and reproduction in any medium, provided the work is properly cited. 